REVIEW ARTICLE

\title{
Indústria do Ovo: qual é o significado e uso dessa expressão?
}

\section{Egg Industry: what is the meaning and use of this term?}

\author{
Maria Antônia Domingues Ramos Pires ${ }^{1 *}$ (D), Andrea Troller Pinto² \\ ${ }^{1}$ Universidade Federal do Rio Grande do Sul (UFRGS), Centro de Estudos e Pesquisas em Agronegócios \\ (CEPAN), Porto Alegre/RS - Brasil \\ ${ }^{2}$ Universidade Federal do Rio Grande do Sul (UFRGS), Departamento de Medicina Veterinária Preventiva, Porto \\ Alegre/RS - Brasil
}

*Corresponding Author: Maria Antônia Domingues Ramos Pires, Universidade Federal do Rio Grande do Sul (UFRGS), Centro de Estudos e Pesquisas em Agronegócios (CEPAN), Av. Bento Gonçalves, 7712, CEP: 90040-

060, Porto Alegre/RS - Brasil, e-mail: mariaantoniadomingues64@gmail.com

\section{Resumo}

No início dos anos 2000, ovos foram reabilitados como saudáveis, sendo alimento nutritivo e economicamente acessível, de uma rica fonte de proteína animal e uma alternativa à carne vermelha. O presente trabalho objetivou identificar se a expressão "Indústria do Ovo" é utilizada em publicações acadêmicas e, se confirmada sua utilização, a que produção se refere frequentemente, bem como em que contexto é utilizada quanto à temática dos artigos científicos. Para tanto, realizou-se uma revisão sistemática da literatura, considerando investigações publicadas nas bases de dados Scopus e Web of Science. Os resultados obtidos demonstraram que a utilização da expressão "Indústria do Ovo" em artigos científicos ocorre desde 1947, sendo empregada para designar, principalmente, a produção comercial de ovos de galinha, cujo uso apresenta linha de tendência crescente. Os artigos com foco em administração, economia, mercados e certificações foram predominantes no emprego da expressão "Indústria do Ovo" no decorrer do período analisado.

Palavras-chave: Análise de conteúdo; Sustentabilidade; Produção animal; Inocuidade; Cadeia produtiva de ovos.

\begin{abstract}
In the early 2000s, eggs were rehabilitated as healthy, nutritious and economically accessible food, a rich source of animal protein and an alternative to red meat. The present work aimed to identify if the expression "Egg Industry" is used in academic publications and, if confirmed its use, to which production refers frequently, as well as in what context is used as the theme of scientific articles. For this, a systematic review of the literature was carried out, considering investigations published in the Scopus and Web of Science databases. The results obtained demonstrated that the use of the term "Egg Industry" in scientific articles has been occurring since 1947, being used mainly to designate the commercial production of chicken eggs, whose use presents a growing trend line. The articles focusing on administration, economy, markets and certifications were predominant in the use of the expression "Egg Industry" during the analyzed period.
\end{abstract}

Keywords: Content analysis; Sustainability; Animal production; Harmlessness; Egg production chain. 


\section{Introdução}

A proteína do ovo tem valor biológico de $94 \%$, sendo o mais alto entre as principais fontes de proteína animal. Esse alimento também tem sido identificado como nutracêutico, ou seja, além da função nutricional, traz benefícios à saúde (Froning, 2007). Assim, ovos são uma rica fonte de proteína animal e uma alternativa saudável à carne vermelha (Shini et al., 2010), sendo considerados alimentos nutritivos e economicamente acessíveis (Wu, 2014).

A reabilitação do ovo como alimento saudável impactou no aumento do consumo e na consequente necessidade de maximizar a produção de ovos comerciais, principalmente por meio da intensificação da produção. Tal reflexo é percebido ao se verificar que a produção mundial de ovos comerciais de galinha aumentou 48,87\% no período compreendido entre 1999 e 2016, com a China respondendo por cerca de 30\% da produção mundial (Food and Agriculture Organization of the United Nations, 2018). Neste cenário, o Brasil elevou sua produção de ovos em 56,06\%, ocupando o sétimo lugar em volume produzido, a qual é destinada praticamente somente ao mercado interno $(99,57 \%)$ e comercializada como ovos de mesa $(84 \%)$ (Associação Brasileira de Proteína Animal, 2017).

A produção comercial de ovos e as indústrias processadoras do produto correspondem a um segmento importante da indústria mundial de alimentos, tanto por suas qualidades nutricionais como por sua versatilidade de uso. O ovo de galinha possui propriedades funcionais únicas, como gelificação, formação de espuma (clara de ovo) e emulsificação (gema de ovo). Tais características tornam esse produto profícuo em diversas preparações da indústria alimentícia (Mine, 2002).

Para atender à demanda, os processos produtivos foram sendo intensificados, de modo que a produção convencional (em gaiolas) responde pela maior parte dos ovos comercializados atualmente em países como Canadá, Estados Unidos e Brasil (Pelletier, 2018; Figueiredo et al., 2018). Nos Estados Unidos, onde mais de $90 \%$ da produção é realizada de forma convencional, os produtores vêm sendo pressionados a mudar suas práticas de produção, particularmente para atender às preocupações concernentes ao bem-estar das aves. Pressões semelhantes no final da década de 1990 impulsionaram a proibição do uso de gaiolas convencionais na União Europeia, a partir de 2012. Esse evento obrigou o desenvolvimento de sistemas de criação alternativos que resultaram em impactos relevantes nos custos e outros aspectos da produção que precisaram ser cuidadosamente considerados, uma vez que podiam afetar a sustentabilidade da produção de ovos (Mench et al., 2011).

Diante do exposto, percebe-se a relevância do ovo enquanto integrante de uma dieta equilibrada e elemento comum de distintas culturas alimentares. Não obstante, tem-se também a contribuição socioeconômica da avicultura de postura comercial e suas peculiaridades, o que reflete na maximização do interesse dos pesquisadores ao longo dos anos, permeando distintas áreas do conhecimento.

Constatada a importância dessa cadeia produtiva, fica o questionamento quanto a verificar se é possível utilizar a expressão "Indústria do Ovo" para designar essa produção. Destarte, o presente estudo tem por objetivo identificar se a expressão "Indústria do Ovo" é utilizada em publicações acadêmicas e, se utilizada, a que tipo de produção se refere frequentemente; também busca identificar em que contexto tal terminologia é comumente empregada; por fim, intenta caracterizar essas publicações científicas quanto aos países onde são desenvolvidas, distribuição temporal e viés de utilização.

Para atingir o objetivo proposto, realizou-se uma revisão sistemática de literatura, por ser um tipo de investigação enfocado em uma questão de pesquisa devidamente definida e que visa identificar, selecionar, avaliar e sintetizar as evidências relevantes disponíveis na literatura. As revisões sistemáticas devem ser abrangentes e não tendenciosas na sua preparação e nos critérios adotados divulgados, de modo que outros pesquisadores possam repetir o procedimento (Galvão \& Pereira, 2014). 
A realização desse tipo de investigação é composta de cinco estágios: (i) definição dos termos e dos métodos de busca; (ii) definição das bases de dados; (iii) seleção dos artigos; (iv) levantamento dos principais pontos de cada artigo; e (v) análise dos resultados (Costa \& Carvalho, 2016).

\section{Material e métodos}

A pesquisa realizada consistiu em uma revisão sistemática da literatura, com enfoque qualitativo, a fim de analisar os documentos publicados e indexados em bases de dados on-line que utilizaram a expressão "Indústria do Ovo" de forma explícita.

O primeiro estágio foi contemplado com a definição do termo a ser pesquisado, "Egg Industry", sem utilizar filtros adicionais. No segundo estágio, definiram-se as bases de dados Scopus e Web of Science para serem investigadas, haja vista sua relevância no âmbito científico. O terceiro estágio correspondeu à seleção dos artigos, com a inserção da palavra-chave "Egg Industry" e sua ocorrência no título, resumo e/ou palavraschave.

A partir de tais orientações, obteve-se um portfólio inicial composto de 166 arquivos contidos na base Scopus e 49 documentos referentes à base de dados Web of Science. Em seguida, procedeu-se à exclusão dos documentos repetidos e daqueles que não estavam disponíveis na íntegra, o que totalizou um portfólio composto de 215 arquivos. Destaca-se que a busca foi realizada em 26 de janeiro de 2018, não havendo restrição quanto à data de publicação e à área do conhecimento contemplada pelos documentos.

Para fundamentar os resultados e discussões, analisaram-se os seguintes aspectos dos artigos selecionados: título, autores, tipo de documento, ano de publicação, periódico em que foi publicado, escopo do periódico, palavras-chave, país de origem dos autores, Digital Object Identifier (DOI), a que se refere a expressão "Egg Industry" no contexto do estudo e qual a ideia central do documento analisado.

Para análise dos dados, procedeu-se com uma análise de conteúdo, que, segundo Bardin (1977), consiste em um conjunto de técnicas de análises das comunicações visando obter, por procedimentos sistemáticos e objetivos de descrição do conteúdo das mensagens, indicadores (quantitativos ou não) que permitem a inferência de conhecimentos relativos às condições de produção e recepção dessas mensagens a fim de explicitar e sistematizar o conteúdo. Assim, segundo o autor, é possível efetuar deduções lógicas e justificadas referentes à origem das mensagens tomadas em consideração.

Utilizou-se da categorização em duas classificações, a partir da leitura do resumo dos documentos e eventual aprofundamento no texto completo, quando necessário (Socorro \& Figueiredo, 2014). Por conseguinte, realizou-se a classificação quanto à temática abordada e ao seguimento produtivo a que se refere a expressão "Egg Industry".

Na Tabela 1, apresentam-se os itens das duas categorias criadas, bem como as siglas correspondentes ao tema central abordado. Destaca-se que, após a análise de conteúdo, realizou-se a classificação segundo as características de cada documento.

Tabela 1. Categorias classificatórias dos artigos analisados conforme o tema abordado com as respectivas siglas e produto objeto do estudo.

\begin{tabular}{cc}
\hline Categorias relativas ao tema central & Categorias de produto \\
\hline AEMC - Administração, Economia, Mercados e Certificações & Frango de corte \\
\hline BEA - Bem-Estar Animal & Industria processadora de ovos \\
\hline CODR - Coprodutos, Resíduos e Desperdícios & Ovos comerciais \\
\hline ET - Equipamentos e Tecnologia & Ovos de pata \\
\hline IPI - Inocuidade e Processos Industriais & Ovos para incubação \\
\hline NS - Nutrição e Saúde (Humana) & \\
\hline PADA - Produção Animal, Doenças e Alimentação & \\
\hline SAIA - Sustentabilidade Ambiental e Impactos Ambientais & \\
\hline SI - Sociais e Ideológicos & \\
\hline
\end{tabular}


Os dados obtidos foram tabulados e dispostos em ordem cronológica crescente. Esse procedimento possibilitou a utilização de ferramentas auxiliares, como tabelas e gráficos dinâmicos, e a confecção de nuvem de palavras no programa Wordclouds.

\section{Resultados e discussão}

Os resultados e discussões estão organizados em três subtópicos, além desta seção inicial, a qual tem como objetivo apresentar as palavras-chave de destaque quando avaliados os documentos que utilizaram a expressão "Indústria do Ovo". A Figura 1 ilustra uma nuvem de palavras predominantes.

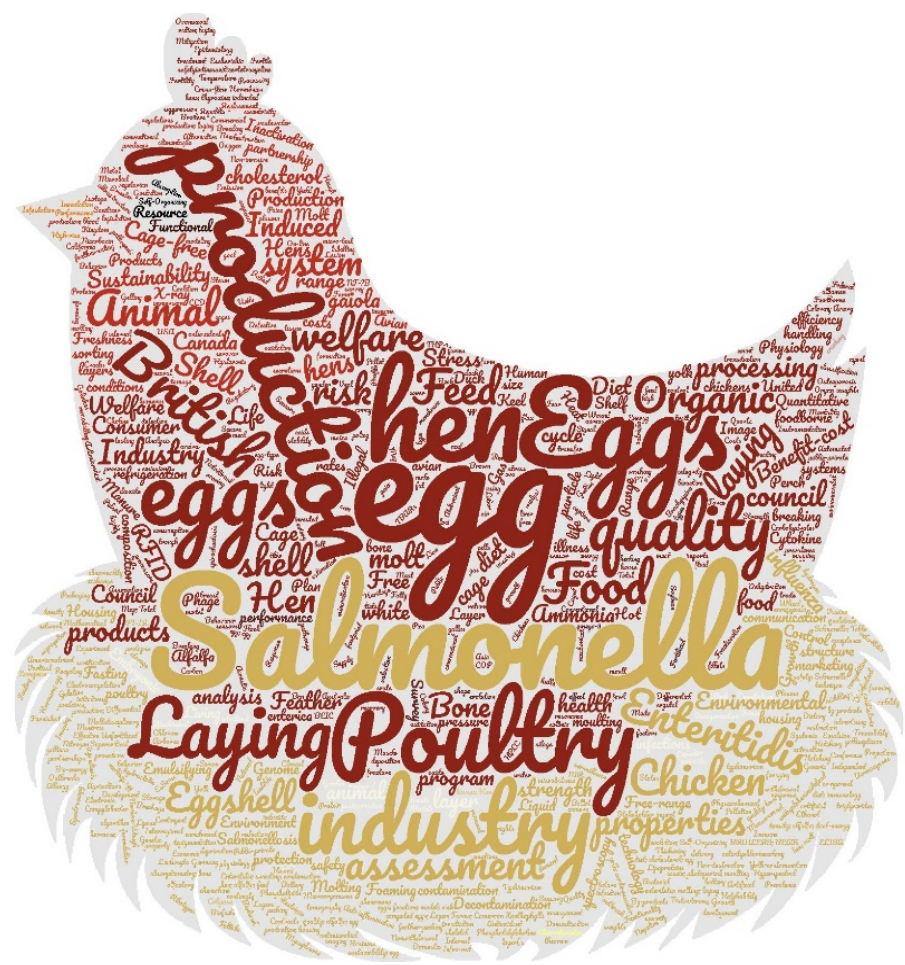

Figura 1. Nuvem de palavras elaborada com as palavras-chave dos documentos selecionados sobre uso acadêmico da expressão "Egg Industry".

\subsection{Resultados bibliométricos}

O levantamento de dados obteve 215 documentos, cuja maior frequência de publicação foi de artigos, com $158(73,5 \%)$ - as demais tipologias estão descritas na Tabela 2.

Tabela 2. Tipo dos documentos nos quais a expressão "Indústria do Ovo" foi utilizada.

\begin{tabular}{ccc}
\hline Tipo de documento & Quantidade & Percentual \\
\hline Artigo & 158 & $73,5 \%$ \\
\hline Capítulo de livro & 7 & $3,3 \%$ \\
\hline Documento de conferência & 15 & $7,0 \%$ \\
\hline Livro & 13 & $6,0 \%$ \\
\hline Nota & 8 & $3,7 \%$ \\
\hline Revisão & 14 & $6,5 \%$ \\
\hline Total & $\mathbf{2 1 5}$ & $\mathbf{1 0 0 , 0 0 \%}$ \\
\hline
\end{tabular}

Fonte: Elaborada pelos autores com dados do portfólio de artigos. 
O registro mais antigo do uso da expressão "Egg Industry" remete-se ao artigo intitulado Scientific Problems in the Dried and Frozen Egg Industry, publicado no periódico Poultry Science, no ano de 1947, e está relacionado à indústria processadora de ovo em pó e líquido congelado (Fletcher \& Brown, 1947). A Figura 2 apresenta um gráfico com a distribuição temporal das publicações com a expressão "Indústria do Ovo" em publicações acadêmicas.

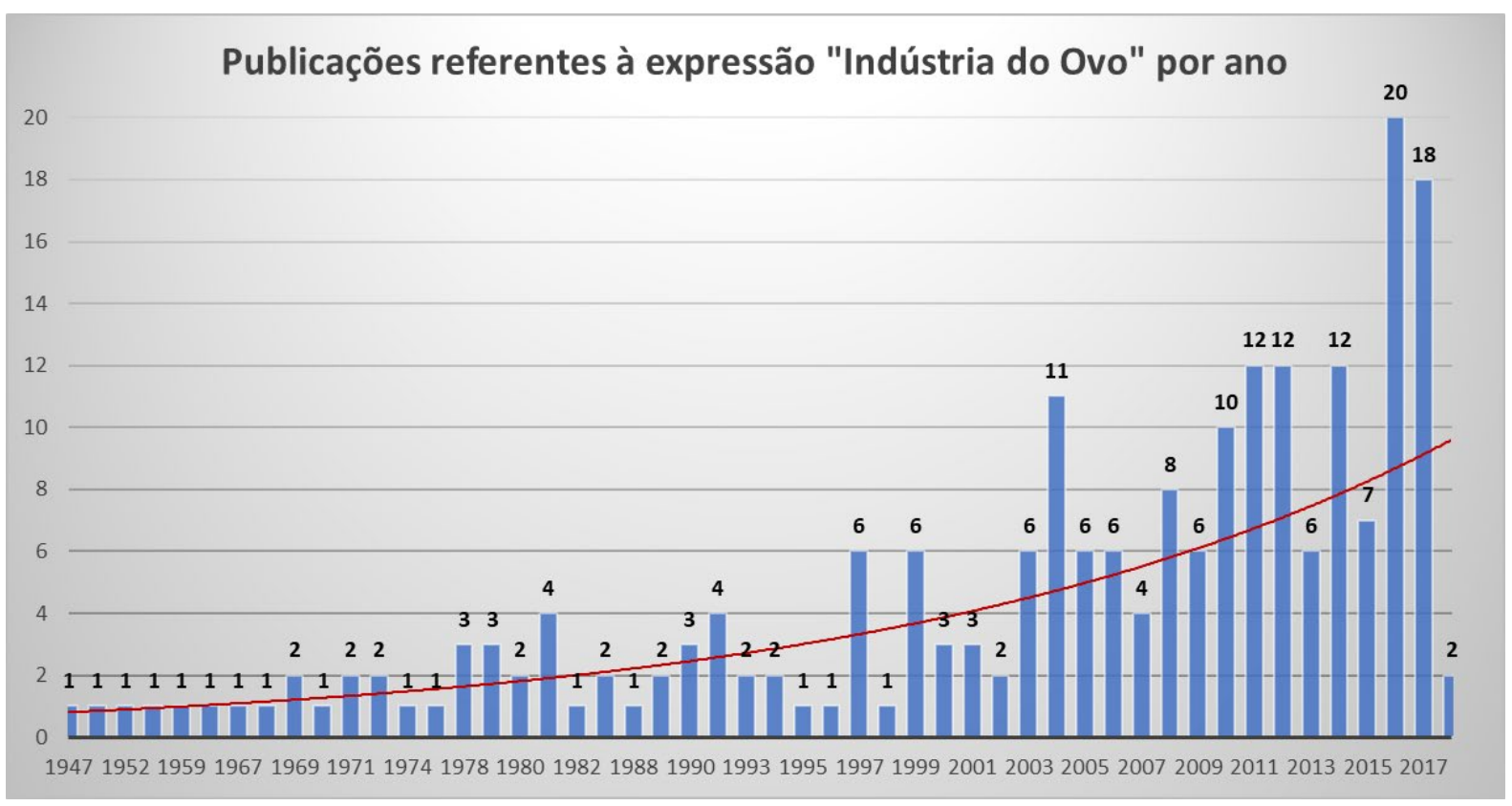

Figura 2. Distribuição temporal das publicações que utilizam a expressão "Indústria do Ovo”. Fonte: Elaborada pelos autores com dados do portfólio de artigos.

Observa-se a tendência de maximização no número de publicações sobre o tema. Não obstante, os Estados Unidos utilizaram com maior frequência a referida expressão, e o periódico Poultry Science lidera no número de publicações. Nas próximas subseções, apresentam-se os dados referentes aos produtos frequentemente relacionados a essa expressão e os resultados relativos às temáticas que utilizam a terminologia "Indústria do Ovo".

\subsection{Produtos designados pela expressão "Indústria do Ovo"}

A expressão "Indústria do Ovo" normalmente está relacionada à produção comercial de ovos, o que não significa necessariamente exclusividade. Assim, os documentos coletados foram categorizados por grupos, mediante análise de conteúdo, e designados como produtos segundo sua relação com a referida expressão, correspondendo, portanto, as seguintes categorias: frango de corte, indústria processadora de ovos (ovo em pó, congelado e outros), ovos comerciais (in natura ou de mesa), ovos de pata e ovos destinados à incubação.

Com base nos resultados obtidos, verificou-se que a expressão "Indústria do Ovo" em 96,74\% dos documentos analisados esteve relacionada à produção comercial de ovos. Todavia, do total do portfólio (215 documentos), 208 tratam diretamente dessa cadeia produtiva, seja na forma de ovos comerciais de mesa (in natura), seja para a indústria processadora de ovos.

Entre os resultados obtidos foi encontrado um documento cujo produto principal é o frango de corte. Nesse documento, a produção de carne de frango é identificada como um subproduto da indústria de ovos. Assim, embora seu objeto de estudo seja a carne, verifica-se claramente que o autor se refere à produção comercial de ovos de galinha quando cita "Indústria do Ovo" (Nir \& Ptichi, 2001). 


\subsection{Resultados referentes à temática central abordada pelos documentos}

A temática principal dos textos selecionados foi outra forma de avalição dos dados, por meio da qual os documentos foram alocados em nove categorias distintas. Em determinados casos, a temática demonstravase circunscrita por outros assuntos, mas cada texto foi classificado em apenas uma categoria considerada predominante e dotada de maior abrangência.

Desde 1947, distintas transformações ocorreram na cadeia produtiva identificada como "Indústria do Ovo". Logo, os estudos foram sendo direcionados para a realidade e adequação das necessidades de seu tempo. A Tabela 2 apresenta a síntese dos resultados quanto às referidas publicações.

A Tabela 3 apresenta a distribuição das temáticas no decorrer do tempo, sendo que, a partir de 2008, ocorreu a maior diversificação de áreas de conhecimento que utilizaram a expressão "Indústria do Ovo", indicando o crescimento de seu uso em publicações acadêmicas em diversas áreas do conhecimento. Nos últimos 10 anos, as publicações mais frequentes estão ligadas à produção animal, administração, segurança alimentar (inocuidade) e processos industriais para sua garantia de inocuidade. Também nesse período surgiram os primeiros documentos que utilizaram a expressão em pesquisas ligadas a questões de sustentabilidade e meio ambiente, uma temática de interesse da sociedade contemporânea.

Tabela 3. Distribuição das publicações segundo sua temática por intervalos de tempo.

\begin{tabular}{ccccc}
\hline Categoria & $\mathbf{1 9 4 7}$ a 1977 & $\mathbf{1 9 7 8}$ a 1997 & $\mathbf{1 9 9 8}$ a 2007 & $\mathbf{2 0 0 8}$ a 2018 \\
\hline Administrativo, Economia, Mercados e Certificações & 15 & 18 & 9 & 24 \\
\hline Bem-Estar Animal & & 1 & 5 & 6 \\
\hline Coprodutos, Resíduos e Desperdícios & & 1 & 1 & 4 \\
\hline Equipamentos e Tecnologia & 1 & 4 & 3 & 17 \\
\hline Inocuidade e Processos Industriais & & 1 & 7 & 20 \\
\hline Nutrição e Saúde (Humana) & & 8 & 22 & 28 \\
\hline Produção Animal, Doenças e Alimentação & & & 5 \\
\hline Sustentabilidade Ambiental e Impactos Ambientais & 1 & 1 & & 2 \\
\hline Sociais e Ideológicos & $\mathbf{1 7}$ & $\mathbf{3 7}$ & $\mathbf{4 8}$ & $\mathbf{1 1 3}$ \\
\hline Total por intervalos de tempo & & &
\end{tabular}

Fonte: Elaborada pelos autores com dados do portfólio de artigos.

Os resultados totais para cada categoria identificam que os documentos que tratam de assuntos administrativos são maioria, com foco, principalmente, durante as primeiras cinco décadas da análise (1947 até 1997). Portanto, observam-se aspectos relacionados ao processo de organização da produção e ao reconhecimento econômico da atividade.

Na categoria denominada Sociais e Ideológicos, estão alocados os documentos de caráter sociológico e de opinião, que não se enquadram como técnicos ou transcrevem questões ideológicas. De modo geral, possuem caráter de crítica a chamada "Indústria do Ovo", como questionamentos sobre a rotulagem enganosa e danosa ao consumidor da criação em larga escala de aves de postura em sistema de produção fora de gaiolas (Carey et al., 2017) ou ainda debates sobre o cultivo de "ovos em fábrica" enquanto um subproduto animal, por exemplo (Varner, 1994).

Sob essa mesma perspectiva, tem-se também um estudo que trata do abate de aves produzido pela "Indústria do Ovo", enfatizando que, exceto em teorias antropocêntricas extremas, matar animais como dano colateral parece, pelo menos, problemático, se não extremamente problemático; contudo, a análise desconsidera questões relevantes, como a segurança alimentar, no sentido de provimento de meios para manter a vida humana (Aerts \& De Tavernier, 2016).

Por sua vez, os documentos que tratam de sustentabilidade e impactos ambientais foram catalogados na categoria intitulada Sustentabilidade Ambiental e Impactos Ambientais, cujo registro pioneiro da utilização da expressão "Indústria do Ovo" está relacionado à minimização da emissão de amônia pelo esterco das aves. 
Assim, apesar de ter efeitos positivos ao meio ambiente, a tônica deste estudo está voltada às condições do ambiente de produção e bem-estar animal (Li et al., 2008).

Não obstante, em outras três investigações foi utilizada a metodologia de Análise de Ciclo de Vida para mensurar os impactos ambientais da produção de ovos. Em dois deles, realizou-se o comparativo entre os impactos ambientais causados pela produção de ovos na década 1960 e da forma atual de produção nos Estados Unidos (Pelletier et al., 2013) e no Canadá (Pelletier, 2018). Já o outro estudo comparou cinco sistemas diferentes de criação de aves e seus respectivos impactos sobre o meio ambiente (Pelletier, 2017).

Na categoria Produção Animal, Doenças e Alimentação, constam os estudos acerca dos sistemas produtivos, doenças que afetam as aves, manejo e trato dos animais, nutrição animal, entre outros aspectos zootécnicos. Logo, essa categoria reúne o segundo maior número de publicações (58 documentos).

Entre os assuntos tratados, a induced moulting, ou "muda forçada", que corresponde a uma técnica controversa de prolongar a vida produtiva das aves - e uma das formas de realizá-la é privar as aves de alimentos, água e luz por tempo determinado -, esteve presente em 16 documentos $(27,6 \%)$. Neste sentido, muitos trabalhos referem-se a formas alternativas e menos agressivas (para as aves) de realizar tal processo. Destaca-se ainda que o primeiro registro observado no portfólio sobre essa prática remonta ao ano de $1996 \mathrm{e}$ propõe a indução da muda forçada por meio do uso de hormônios (Hussein, 1996).

Nos documentos dessa categoria, a expressão "Indústria do Ovo" também foi utilizada para designar outras formas de criação que não a convencional em gaiolas. Esse é o caso do artigo que trata da densidade demográfica de aves por hectare nos sistemas de criação com aves livres e sua normatização na Austrália (Singh et al., 2017).

Não obstante, na categoria Nutrição e Saúde (Humana), alocaram-se os documentos referentes ao valor nutricional do ovo e sua importância como alimento. Nove artigos foram catalogados nessa categoria, dos quais um se refere à reabilitação do ovo como alimento, publicado em 2015, e aborda a reação dos produtores de ovos, indústria e cientistas para provar a qualidade nutricional do alimento ovo, após a limitação de seu consumo indicada em 1968 pela American Heart Association (McNamara, 2015).

Nessa mesma linha de estudo, porém com outra abordagem, um estudo contesta a total absolvição dos ovos, referindo-se ao seu consumo como prejudicial à saúde e afirmando que, após a convicção de propaganda falsa, a "Indústria do Ovo" gastou centenas de milhões de dólares para convencer o público, os médicos e os formuladores de políticas de que o colesterol dietético e a gema de ovo são inofensivos. Seu autor conclui que existem boas razões para recomendar que as pessoas em risco de doença cardiovascular devem limitar até $200 \mathrm{mg} /$ dia a ingestão de colesterol e gema de ovo (Spence, 2016).

A segurança alimentar sob a ótica da inocuidade e os processos para sua garantia correspondem ao foco principal da categoria denominada Inocuidade e Processos Industriais, na qual constam 31 documentos que utilizaram a expressão "Indústria do Ovo", sendo 7 direcionados à indústria processadora de ovos e 24 à produção comercial de ovos de galinha para comercialização in natura. A essência desses estudos diz respeito à contaminação, principalmente por Salmonella, de modo que, em $48,4 \%$ deles, o termo é encontrado no título.

Por sua vez, na categoria Equipamentos e Tecnologia, encontram-se os documentos que contemplam assuntos relativos a equipamentos, sistemas produtivos ou industriais inovadores, biotecnologia e genética. Assim, 24 documentos possuíam essa temática, dos quais 18 se referiam a ovos comerciais, 2, à indústria processadora, 3, à incubação, e somente 1, à produção de ovos de pata.

Destaca-se que os documentos abordam assuntos variados, por exemplo, recomendações sobre construções e equipamentos para unidades produtoras de ovos que possibilitem a expansão da atividade (Neyeloff et al., 1979). Também há a engenharia genética e sua utilização como ferramenta para solução de problemas ósseos das aves de postura (Guo et al., 2017) e as técnicas e equipamentos para detecção dos ovos férteis e fecundos de galinhas e patas (Valdez et al., 2017; Fasenko, 2007; Lawrence et al., 2006). 
O crescimento da indústria processadora de ovos motivou estudos acerca da tecnologia de descontaminação de ovos cozidos por UV pulsado, sendo considerada uma técnica eficaz para esterilização superficial de ovos cozidos. Nesse sentido, a alta pressão hidrostática (HHP) foi testada como alternativa para substituir a pasteurização por calor e foi considerada eficaz como tecnologia de garantia da inocuidade de ovos processados, contribuindo também para melhorar a eficiência energética da indústria (Ercan \& Demirci, 2016).

Os documentos relativos ao aproveitamento de coprodutos, resíduos e desperdícios, seja por seu valor econômico, seja como forma reduzir o impacto ambiental, estão reunidos na categoria denominada Coprodutos, Resíduos e Desperdícios. Tal temática foi identificada no artigo que trata do aproveitamento das aves de descarte, ao final do período de postura, e que, apesar de possuir um enfoque econômico, também aborda aspectos relacionados à destinação ecologicamente correta por meio do aproveitamento como fonte de proteína (Kondaiah \& Panda, 1992).

Nesta mesma linha de pesquisa, verificou-se a viabilidade de aproveitamento dos pintinhos machos das linhagens de postura, que são descartados no momento da sexagem (ao nascer) e seu potencial para produção de carne. Também destacam-se elementos relacionados à sustentabilidade ambiental da cadeia produtiva e sua ligação com o aproveitamento de descartes da produção (Bertechini et al., 2014). Não obstante, um estudo avaliou e aprovou a casca de ovo como potencial despoluidor de águas e solo, por sua capacidade de adsorver poluentes, em virtude de sua composição e porosidade (He et al., 2016). Sob essa mesma perspectiva, estudou-se o aproveitamento da membrana de casca do ovo (ESM) como curativo para ferimentos cutâneos, por exemplo, queimaduras e cortes. Assim, trata-se de um tratamento alternativo utilizado pela sabedoria popular por mais de 400 anos em países asiáticos e pode estar disponível em grandes quantidades a partir da "Indústria do Ovo". Seus autores concluíram que o pó de ESM processado e seus componentes de carboidratos solúveis possuem propriedades anti-inflamatórias, demonstrando o potencial da ESM como um novo curativo biológico para o tratamento de ferimentos com processos inflamatórios crônicos (Vuong et al., 2017).

$\mathrm{Na}$ categoria relacionada ao Bem-Estar Animal, estão contidos os documentos que tratam diretamente do bem-estar das aves, contestando a forma convencional da produção de ovos comerciais em gaiolas. Observou-se que, sob tal abordagem, o surgimento de publicações utilizando a expressão "Indústria do Ovo" ocorreu em 1997, e, nessa categoria, compilaram-se 12 estudos.

A ocorrência de investigações sobre essa temática coincide com o período que antecedeu a proibição de criação de aves em gaiolas na União Europeia e as discussões relativas à sua concretização, ocorrida em 1999 e efetivamente implementada em 2012. Essa proibição levou ao desenvolvimento de sistemas alternativos de alojamento, como as gaiolas enriquecidas.

Uma pesquisa realizada nos Estados Unidos abordou a criação de aves fora de gaiolas e demonstrou que menos de 5\% da produção de ovos ocorre em aves livres. Entretanto, esse tipo de criação cresceu, em parte, por causa de incentivos políticos e de mercado para os sistemas que proporcionam às galinhas maior liberdade comportamental. Logo, a adoção de novos sistemas de alojamento pode acarretar efeitos substanciais sobre os custos e outros aspectos da produção de ovos em escala regional e nacional, com possíveis efeitos negativos e positivos que precisam ser cuidadosamente considerados (Mench et al., 2011). A criação de aves livres de gaiolas pode trazer a ocorrência de um fenômeno denominado smothering, ou sufocamento, que ocorre quando as aves se agrupam de maneira que resulta na morte por sufocação, sendo um grave problema de bem-estar e preocupação econômica para a "Indústria de Ovos" (Rayner et al., 2016).

Os 12 trabalhos catalogados possuem enfoques diversos, e, por tratar-se de um assunto controverso, seu estudo implica diversos olhares e distintas ponderações. $\mathrm{O}$ bem-estar pode ser abordado em termos do sistema de produção a ser usado e com referência a questões como corte do bico e tempo de transporte (Gittins, 2004).

A categoria denominada Administrativo, Economia, Mercados e Certificações contempla o maior número de publicações (66 documentos), de vários tipos, como: 51 artigos, 2 documentos de conferência, 2 livros, 8 
notas e 3 revisões. Os estudos abrangem questões econométricas e mercadológicas, estratégias de mercado, políticas de preço e documentos relacionados a problemas de gestão da atividade produtiva designada pela expressão "Indústria do ovo".

Destaca-se que, nessa categoria, todos os documentos são relativos ao produto ovo comercial, segundo os critérios descritos na metodologia deste estudo. Nos últimos 10 anos, foram encontradas 22 publicações que retratam as questões atuais da atividade produtiva, como a proibição a partir de 2012 da criação de poedeiras em gaiolas na União Europeia. Desses documentos, 7 referem-se a notas publicadas pela Food Manufacture, que estão relacionadas a questões sobre a coordenação da atividade após a proibição de criação em gaiolas e são originárias da União Europeia; por exemplo, a nota que trata do mercado de ovos do Reino Unido sob ameaça de 12,5 mil milhões de ovos não conformes (Gibbons, 2013).

Também há um estudo que apresenta uma série de preocupações contemporâneas no que se refere à produção de alimentos, ou seja, produzir mais com o menor impacto possível ao meio ambiente, além das possibilidades de parcerias público-privadas como forma de apoiar iniciativas de pesquisa (Mench et al., 2016).

\section{Considerações finais}

Os dados apresentados indicam que a expressão "Egg Industry" ou "Indústria do Ovo" é utilizada desde o ano de 1947 em publicações acadêmicas, tendo sido verificado que seu emprego se relaciona, principalmente, à produção comercial de ovos de galinha e à indústria processadora de ovos.

Considerando a quantidade total de 215 documentos analisados, conclui-se ser adequado designar a produção comercial de ovos como "Indústria do Ovo", uma vez que 208 documentos (96,75\%) estão relacionados diretamente a essa cadeia produtiva, seja na forma de ovos comerciais de mesa (in natura), seja na produção destinada à indústria processadora de ovos. Destaca-se ainda que o emprego da referida expressão em documentos científicos demonstra uma linha de tendência crescente ao longo dos anos.

Infere-se que a expressão "Indústria do Ovo" pode ser utilizada para designar a avicultura de postura comercial e está relacionada a uma forma organizada e coordenada de produção, configurando uma cadeia produtiva complexa. Tal terminologia sintetiza e representa com adequação essa realidade, não tendo relação com um processo fabril propriamente dito, mas com a organização por ele exigido, de forma a garantir mercado para o produto, qualidade, preço e cumprimento das exigências legais estabelecidas.

\section{Referências}

Aerts, S., \& De Tavernier, J. 11. Killing animals as a matter of collateral damage. In F. L. B. Meijboom \& E. N. Stassen (Eds.), The end of animal life: A start for ethical debate. The Netherlands: Wageningen Academic Publishers, 2016. p. 167-186. http://dx.doi.org/10.3920/978-90-8686-808-7_11.

Associação Brasileira de Proteína Animal - ABPA. (2017). Relatório anual da ABPA 2017. São Paulo: ABPA. Recuperado em 5 de julho de 2018, de http://abpa-br.com.br/storage/files/3678c_final_abpa_relatorio_anual_2016_portugues_web_reduzido.pdf

Bardin, L. (1977). Análise de conteúdo. Lisboa: Edições 70.

Bertechini, A. G., Mazzuco, H., Rodrigues, E. C., \& Ramos, E. M. (2014). Study of the utilization of light egg-type males: A proposal for the sustainability of the egg industry. Poultry Science, 93(3), 755-761. PMid:24604872. http://dx.doi.org/10.3382/ps.2013-03462

Carey, R., Parker, C., \& Scrinis, G. (2017). Capturing the meaning of "free range": The contest between producers, supermarkets and consumers for the higher welfare egg label in Australia. Journal of Rural Studies, 54, $266-275$. http://dx.doi.org/10.1016/j.jrurstud.2017.06.014

Costa, D. F., \& Carvalho, F. M. (2016). Relação entre gerenciamento de resultado e governança corporativa: Construindo um referencial teórico a partir de uma revisão sistemática da literatura. ForScience, 4(1), 20-41.

http://dx.doi.org/10.29069/forscience.2016v4n1.e182

Ercan, D., \& Demirci, A. (2016). Decontamination of hard-cooked eggs by pulsed UV processing. In Proceedings of the 2016 ASABE International Meeting. St. Joseph: American Society of Agricultural and Biological Engineers. Recuperado em 5 de julho de 2018, de http://elibrary.asabe.org/azdez.asp?JID=5\&aid=47170\&abstract=162456233.htm\&cid=orl2016\&t=3 
Fasenko, G. M. (2007). Egg storage and the embryo. Poultry Science, 86(5), 1020-1024. PMid:17435042. http://dx.doi.org/10.1093/ps/86.5.1020

Figueiredo, E., Mazzuco, H., \& Henn, J. D. (2018). Produção e mercado: os ovos que consumimos (pp. 1-2). Recuperado em 5 de julho de 2018, de https://www.infoteca.cnptia.embrapa.br/infoteca/bitstream/doc/1083165/1/final8480.pdf

Fletcher, D., \& Brown, W. (1947). Scientific problems in the dried and frozen egg industry. Poultry Science, 26(5), 539-539.

Food and Agriculture Organization of the United Nations - FAO. (2018). Production índices. Rome: FAO. Recuperado em 27 de novembro de 2018, de http://www.fao.org/faostat/en/\#data/QI

Froning, G. (2007). Egg products industry and future perspectives. In Y. Mine (Ed.), Egg bioscience and biotechnology (pp. 307325). Chichester: John Wiley \& Sons.

Galvão, T., \& Pereira, M. (2014). Revisões sistemáticas da literatura: Passos para sua elaboração. Epidemiologia e Serviços de Saúde: Revista do Sistema Unico de Saúde do Brasil, 23(1), 183-184. http://dx.doi.org/10.5123/S1679-49742014000100018

Gibbons, L. (2013, october 28). UK egg market under threat from 12.5bn non-compliant eggs. Food Manufacture.

Gittins, J. (2004). Quality assurance (Vol. 27). Cambridge: Cabi Publishing.

Guo, J., Sun, C., Qu, L., Shen, M., Dou, T., Ma, M., Wang, K., \& Yang, N. (2017). Genetic architecture of bone quality variation in layer chickens revealed by a genome-wide association study. Scientific Reports, 7(1), 45317. http://dx.doi.org/10.1038/srep45317

He, W., Yang, S., \& Zhang, G. (2016). Recent studies on eggshell as adsorption material. Nongye Gongcheng Xuebao. Nongye Gongcheng Xuebao, 32, 297-303.

Hussein, A. S. (1996). Induced moulting procedures in laying fowl. World's Poultry Science Journal, 52(2), 184-187. http://dx.doi.org/10.1079/WPS19960014

Kondaiah, N., \& Panda, B. (1992). Processing and utilization of spent hens. World's Poultry Science Journal, 48(3), 255-268. http://dx.doi.org/10.1079/WPS19920020

Lawrence, K. C., Smith, D. P., Windham, W. R., Heitschmidt, G. W., \& Park, B. (2006). Egg embryo development detection with hyperspectral imaging. In Proceedings of SPIE - The International Society for Optical Engineering. Boston. http://dx.doi.org/10.1117/12.686303.

Li, H., Xin, H., Liang, Y., \& Burns, R. T. (2008). Reduction of ammonia emissions from stored laying hen manure through topical application of zeolite, Al+clear, ferix-3, or poultry litter treatment. Journal of Applied Poultry Research, 17(4), 421-431. http://dx.doi.org/10.3382/japr.2007-00076

McNamara, D. J. (2015). The fifty year rehabilitation of the egg. Nutrients, 7(10), 8716-8722. PMid:26506379. http://dx.doi.org/10.3390/nu7105429

Mench, J. A., Sumner, D. A., \& Rosen-Molina, J. T. (2011). Sustainability of egg production in the United States-the policy and market context. Poultry Science, 90(1), 229-240. PMid:21177465. http://dx.doi.org/10.3382/ps.2010-00844

Mench, J. A., Swanson, J. C., \& Arnot, C. (2016). The coalition for sustainable egg supply: A unique public-private partnership for conducting research on the sustainability of animal housing systems using a multistakeholder approach. Journal of Animal Science, 94(3), 1296-1308. PMid:27065290. http://dx.doi.org/10.2527/jas.2015-9680

Mine, Y. (2002). Recent advances in egg protein functionality in the food system. World's Poultry Science Journal, 58(1), 31-39. http://dx.doi.org/10.1079/WPS20020005

Neyeloff, S., Byler, R. K., \& Muller, H. D. (1979). Housing recommendations for a rapidly expanding egg industry. St. Joseph: American Society of Agricultural Engineers.

Nir, I., \& Ptichi, I. (2001). Feed particle size and hardness: Influence on performance, nutritional, behavioral and metabolic aspects. Wageningen: Wageningen Academic Publishers.

Pelletier, N. (2018). Changes in the life cycle environmental footprint of egg production in Canada from 1962 to 2012. Journal of Cleaner Production, 176, 1144-1153. http://dx.doi.org/10.1016/j.jclepro.2017.11.212

Pelletier, N. (2017). Life cycle assessment of Canadian egg products, with differentiation by hen housing system type. Journal of Cleaner Production, 152, 167-180. http://dx.doi.org/10.1016/j.jclepro.2017.03.050

Pelletier, N., Ibarburu, M., \& Xin, H. (2013). A carbon footprint analysis of egg production and processing supply chains in the Midwestern United States. Journal of Cleaner Production, 54, 108-114. http://dx.doi.org/10.1016/j.jclepro.2013.04.041

Rayner, A. C., Gill, R., Brass, D., Willings, T. H., \& Bright, A. (2016). Smothering in UK free-range flocks. Part 2: Investigating correlations between disease, housing and management practices. The Veterinary Record, 179(10), 252. PMid:27353872. http://dx.doi.org/10.1136/vr.103701

Shini, S., Huff, G. R., Shini, A., \& Kaiser, P. (2010). Understanding stress-induced immunosuppression: Exploration of cytokine and chemokine gene profiles in chicken peripheral leukocytes. Poultry Science, 89(4), 841-851. PMid:20308420. http://dx.doi.org/10.3382/ps.2009-00483

Singh, M., Ruhnke, I., de Koning, C., Drake, K., Skerman, A. G., Hinch, G. N., \& Glatz, P. C. (2017). Demographics and practices of semi-intensive free-range farming systems in Australia with an outdoor stocking density of $\leq 1500$ hens/hectare. PLoS One, 12(10), e0187057. PMid:29065169. http://dx.doi.org/10.1371/journal.pone.0187057

Socorro, T. C., \& Figueiredo, M. A. (2014). Análise de conteúdo temático-categorial: Considerações teóricas e práticas. In Semana de Pesquisa da Universidade Tiradentes (SEMPESq) (No. 16). Tiradentes. 
Indústria do Ovo: qual é o significado e uso dessa expressão?

Pires, M. A. D. R., \& Pinto, A. T.

Spence, J. D. (2016). Dietary cholesterol and egg yolk should be avoided by patients at risk of vascular disease. Journal of Translational Internal Medicine, 4(1), 20-24. PMid:28191513. http://dx.doi.org/10.1515/jtim-2016-0005

Valdez, M. A. T., Watt, P. A. S. T., \& Mappatao, G. P. (2017). Automated fertilized duck egg sorting system using image processing. Advanced Science Letters, 23(6), 5191-5194. http://dx.doi.org/10.1166/asl.2017.7339

Varner, G. E. (1994). What's wrong with animal by-products? Journal of Agricultural \& Environmental Ethics, 7(1), 7-17. http://dx.doi.org/10.1007/BF01997220

Vuong, T., Rønning, S., Suso, H., Schmidt, R., Prydz, K., Lundström, M., Moen, A., \& Pedersen, M. (2017). The extracellular matrix of eggshell displays anti-inflammatory activities through NF-kB in LPS-triggered human immune cells. Journal of Inflammation Research, 10, 83-96. PMid:28740415. http://dx.doi.org/10.2147/JIR.S130974

Wu, J. (2014). Eggs and egg products processing. In S. Clark, S. Jung \& B. Lamsal (Eds.), Food processing: Principles and applications (pp. 437-455). Chichester: John Wiley \& Sons. http://dx.doi.org/10.1002/9781118846315.ch19.

Funding: None. 